\title{
Projeto Partilhar é Especial: Um Relato de Experiência Sobre sua Primeira Etapa
}

\author{
Ermelindo P.B. Schultz ${ }^{1}$, Laura Sanchez García ${ }^{1}$, Maíra Codo Canal ${ }^{1}$, \\ Deogenes P. S. Junior ${ }^{1}$, Roberto Pereira ${ }^{1}$ \\ ${ }^{1}$ Departamento de Informática - Universidade Federal do Paraná (UFPR) \\ Curitiba - PR - Brasil
}

\begin{abstract}
In this paper we present the participatory design of the first version of the social network named "Share is Special". This social network aims to promote a virtual space for Special Education professionals to socialize their knowledge and their pedagogical practices. We present the inputs and outputs of five participatory workshops conducted with a Special School, the results of the design process and our reflections on this experience.
\end{abstract}

Resumo. Neste trabalho apresentamos o design participativo da primeira versão da rede social "Partilhar é Especial". Esta rede social tem como objetivo promover um espaço virtual para os profissionais da Educação Especial socializarem seus conhecimentos e suas praticas pedagógicas. Apresentamos as entradas e saídas de cinco oficinas participativas conduzidas com uma Escola Especial, os resultados do processo de design e nossas reflexões a respeito desta experiência.

\section{O projeto Partilhar é Especial}

Em 2016, participamos do VI Fórum Internacional sobre Surdocegueira e Deficiência Sensorial Múltipla. Os pesquisadores e profissionais que fizeram apresentações no evento nos trouxeram duas de suas angústias ${ }^{1}$ : a rejeição pela academia de resultados de suas pesquisas e falta de interesse da indústria de software em construir tecnologias para estas comunidades, uma vez que apresentam pouco potencial de lucro.

Contribuindo para a discussão sobre estas questões, pesquisadores da Associação Educacional para Múltipla Deficiência (AHIMSA) http: / / www . ahimsa . org • br/, da cidade de São Paulo, reportaram uma dissociação entre professores do AEE (Atendimento Educacional Especializado) e professores do turno regular, apontando a necessidade de encontrar maneiras de promover o trabalho em conjunto destes dois perfis de profissionais.

Este conjunto de fatores nos levou a conceber uma solução baseada no Ambiente Pedagógico Colaborativo (APC), desenvolvido dentro do contexto de um programa governamental de inclusão digital chamado Paraná Digital (PRD) [Menezes 2008]. O PRD foi uma iniciativa de 2003 do governo do Paraná para incentivar o uso de tecnologias educacionais nas escolas. Foram instalados computadores em todas as escolas públicas do Estado do Paraná e desenvolvida uma arquitetura baseada em software livre para a gerência dos

\footnotetext{
${ }^{1}$ Salientamos que estas angústias não implicam em generalizações sobre a academia ou a indústria. Independente de validação empírica, foram estas percepções dos pesquisadores e educadores da educação especial que motivaram a proposição deste projeto.
} 
VII Congresso Brasileiro de Informática na Educação (CBIE 2018)

Anais dos Workshops do VII Congresso Brasileiro de Informática na Educação (WCBIE 2018)

laboratórios [Castilho et al. 2007]. Foi construído também o portal Dia-a-Dia educação ( http://www.diaadia.pr.gov.br/), em que se encontrava o APC. Mudanças políticas no Estado fizeram com que o governo adotasse software privado e colocasse o APC em desuso.

O APC foi construído com o objetivo de organizar todos os conteúdos relacionados ao sistema de ensino sob responsabilidade do Estado do Paraná e para promover comunidades de prática nas quais os professores paranaenses pudessem criar e compartilhar seus próprios objetos de aprendizagem (nominados Objetos de Aprendizagem Colaborativos, ou OAC) [Menezes 2008], que poderiam ser atividades, imagens, curiosidades, relatórios, entre outros [Menezes 2008]. A iniciativa foi acompanhada por ações administrativas, como a criação de grupos específicos para a avaliação das contribuições, a remuneração por meio de incentivos na progressão de carreira dos professores, e a criação de novo perfil dentro da malha educacional para assumir o papel de um multiplicador de conhecimento de software livre.

Apesar do comprometimento governamental, da boa infraestrutura técnica para a época e das possibilidades inovadoras para a formação continuada de professores, problemas ocorreram. Em uma análise sobre o modelo didático-tecnológico do portal [Menezes 2008], foi observado que os OACs tiveram pouca colaboração e que a maioria da produção de OACs ocorreu apenas em workshops organizados pelo Estado, não voluntariamente pelos professores. A análise apontou como uma das possíveis causas a burocracia para compartilhar um OAC, uma vez que este devia passar por um rigoroso processo de avaliação antes de ser aceito (quando era) e publicado - um fator de desmotivação para os professores.

A partir da análise de Menezes, trouxemos a hipótese de que os professores não tiveram voz ativa nas decisões tomadas na construção do APC. Esta hipótese é fortalecida pelo estudo de Basniak sobre o PRD [Basniak 2016]. A autora analisou documentos oficiais e entrevistou alguns atores que fizeram parte do processo, e concluiu que não houve consulta à comunidade escolar durante o desenvolvimento do projeto, pontuando várias críticas sob a ótica da falta da participação dos professores nas tomadas de decisões na época, e trazendo à tona a importância de ouvir os principais atores do processo nas políticas de desenvolvimento e implantação de tecnologias educacionais. Estes fatores nos levaram a procurar abordagens metodológicas que valorizassem as vozes dos profissionais da Educação Especial no processo de desenvolvimento do ambiente deste trabalho, adotando um referencial e abordagem participativos para o design. Nascia o projeto Partilhar é Especial.

O processo de construção do ambiente terá continuidade por tempo indeterminado, acompanhando seu uso e disseminação. No presente artigo, apresentamos o processo organizado, seus fundamentos, e os resultados do primeiro ciclo do processo, conduzido com uma escola especial, descrevendo as práticas e os resultados discutidos. $\mathrm{O}$ artigo é organizado da seguinte forma: na seção 2 apresentamos uma revisão de literatura. Na seção 3 apresentamos a metodologia adotada. Na seção 4 as oficinas são descritas e discutidas. Na seção 5 apresentamos as lições aprendidas do processo. Na seção 6 as conclusões são apresentadas. 
VII Congresso Brasileiro de Informática na Educação (CBIE 2018)

Anais dos Workshops do VII Congresso Brasileiro de Informática na Educação (WCBIE 2018)

\section{Revisão de Literatura}

O Design Participativo (DP) oferece princípios, métodos e práticas para a descoberta e a criação conjunta com os participantes, ao mesmo tempo em que explicita as limitações e as oportunidades que os participantes enfrentam no seu contexto [Ehn 2017]. No início da década de 70, na região Escandinava do pós-guerra, os trabalhadores adquiriram mais poder nas tomadas de decisões no ambiente de trabalho. Entretanto, estes ainda não eram envolvidos nas decisões sobre implantação de sistemas computacionais neste mesmo ambiente. O DP emerge para se posicionar ao lado dos trabalhadores e seus sindicatos, visando dar voz às pessoas excluídas dos processos de decisão sobre implantação e desenvolvimento de tecnologias computacionais.

O cenário político e econômico mudou com o tempo e os sindicatos perderam a força que tinham na época dos projetos pioneiros. O DP ocupou outros espaços, tais como movimentos sociais e esferas públicas, se tornando um campo diverso, com diferentes conotações e abordagens. O movimento se disseminou ao redor do mundo, levando para diversos contextos sociais e políticos mundiais uma visão alternativa na construção e apropriação de tecnologias - uma visão democrática, de múltiplas vozes e de aprendizagem mútua [Kensing and Greenbaum 2013]. Ao trazer a visão dos pioneiros do DP para nosso processo, buscamos atacar as questões levantadas por Basniak. Buscamos dar voz às pessoas que geralmente são excluídas nas tomadas de decisões sobre construção e implantação de tecnologias que afetam seu próprio trabalho e suas próprias vidas, como foram os atores educacionais no PRD, tendo como ponto de partida sua realidade e suas reais necessidades.

O DP reconhece e valoriza o caráter situado do design, no qual questões culturais, socioeconômicas e de valores são aspectos críticos a serem entendidos e respeitados. Assim, para identificar trabalhos relacionados foram analisados os trabalhos publicados nos repositórios dos principais fóruns e revistas relacionados à informática na educação brasileiros (SBIE, WIE, RBIE e IHC) desde 2008. Como exemplo de trabalho encontrado, tem-se o ambiente chamado Wikitas, teorizado por [da Silva and Prietch 2016] com o objetivo de permitir que professores e intérpretes compartilhem e encontrem materiais que assistam seus alunos com surdez. Foram apresentados o resultado da revisão sistemática e o conjunto de requisitos provenientes da aplicação de técnicas de elicitação e análise de requisitos. O trabalho não apresenta uma implementação funcional, uma vez que a prototipação seria realizada em trabalhos futuros.

Outros trabalhos apresentam experiências híbridas de formação de professores mesclando encontros presenciais e uso de tecnologia colaborativa, como no caso de [Borges et al. 2016]. Os autores apresentam um estudo de caso no qual professores que atuam no ensino técnico-profissional tiveram encontros presenciais e formaram grupos dentro do ambiente Moodle. Em [Barcelos et al. 2013], os autores relatam um processo de formação para professores de Matemática no qual os professores utilizaram uma rede social criada com a plataforma Elgg.

Estes trabalhos apontam para as potencialidades da colaboração e socialização em ambientes virtuais por professores em processo de formação continuada. Porém, estas tecnologias foram utilizadas/criadas dentro de contextos bem específicos e delimitados. Além disso, o foco destes trabalhos não foi a Educação Especial. 
VII Congresso Brasileiro de Informática na Educação (CBIE 2018)

Anais dos Workshops do VII Congresso Brasileiro de Informática na Educação (WCBIE 2018)

O TNR http: / / tnr.nied.uni camp.br/, Todos Nós em Rede, é uma rede social criada para apoiar a educação continuada de professores brasileiros que atuam na educação inclusiva [Baranauskas 2014]. O TNR foi construído de uma maneira socialmente consciente e participativa, com base em workshops com professores de diferentes regiões do país. Neste espaço, os professores podem buscar soluções para seus problemas cotidianos e compartilhar ideias e casos bem sucedidos ou ainda não resolvidos. $\mathrm{O}$ TNR foi concebido com professores do AEE, enquanto nosso trabalho busca envolver um público mais abrangente desde o início. Além disto, o TNR não se sustentou como esperado, indicando que as práticas participativas devem continuar indefinidamente - como propomos neste trabalho.

\section{Metodologia}

Apresentamos este trabalho como um relato do que consideramos a primeira etapa do projeto Partilhar é Especial. Esta etapa foi conduzida em parceria com uma escola de educação especial pública. O perfil de seus alunos é diversificado. A escola atende crianças com cegueira e deficiência visual, autismo, deficiência motora, entre outras.

Foram realizadas cinco oficinas participativas (ver Tabela 1 ) e reuniões com a equipe pedagógica da escola após cada oficina. Todas as oficinas ocorreram nas dependências da escola, utilizando desde salas de aula até a biblioteca. As oficinas aconteceram em dois momentos: em grupos de estudos e nos horários de permanência dos profissionais. Em ambos os casos, os participantes apareceram voluntariamente e espontaneamente nas oficinas. Tínhamos, portanto, poucas informações sobre quantos profissionais participariam antes de cada oficina.

Um relatório foi escrito após cada oficina e reunião. Cada relatório continha a descrição detalhada da oficina ou reunião e também os comentários mais relevantes dos participantes.

\begin{tabular}{|c|c|c|c|}
\hline & Número de Participantes & Duração & Objetivos \\
\hline 1 & 18 & $50 \mathrm{~min}$. & $\begin{array}{c}\text { Apresentar a ideia aos participantes; } \\
\text { Conhecer a estrutura e o trabalho da escola; }\end{array}$ \\
\hline 2 & 17 & $1 \mathrm{~h} 30 \mathrm{~min}$ & $\begin{array}{c}\text { Identificar as partes interessadas; } \\
\text { Gerar ideias e levantar as necessidades; }\end{array}$ \\
\hline 3 & 6 & $30 \mathrm{~min}$ & Detalhar as ideias; \\
\hline 4 & 6 & $45 \mathrm{~min}$ & Detalhar as ideias; \\
\hline 5 & 23 & $1 \mathrm{~h} 30 \mathrm{~min}$ & Apresentar e avaliar a primeira versão \\
\hline
\end{tabular}

Tabela 1. Visão geral das Oficinas

Em [Muller et al. 1997], os autores apresentam uma taxonomia que mostra como métodos do DP podem ser utilizados nas diversas etapas do ciclo de desenvolvimento de software e apresentam um apêndice com 61 técnicas resumidas com suas respectivas referências. As práticas participativas foram escolhidas a partir desta taxonomia.

\section{Oficinas}

Nesta seção apresentamos e discutimos as oficinas participativas conduzidas. Na Oficina 1 apresentamos o projeto aos participantes que compareceram ao grupo de estudo. As ideias e necessidades levantadas em duas reuniões anteriores com as pesquisadoras da 
VII Congresso Brasileiro de Informática na Educação (CBIE 2018)

Anais dos Workshops do VII Congresso Brasileiro de Informática na Educação (WCBIE 2018)

AHIMSA foram trazidas para a primeira oficina como ponto de partida. A apresentação do projeto durou 15 minutos e o restante do tempo foi uma conversa com os participantes.

Apresentamos nosso grupo de pesquisa - visões, princípios, posições e trabalhos anteriores relacionados à Educação Especial - e respondemos a questões, ouvindo as percepções e opiniões dos professores a respeito de nossa apresentação. Os participantes nos ensinaram sobre o modo como a escola funciona, como também os problemas institucionais que os incomodam. Na sequência, os participantes já trouxeram ideias para o projeto, que serviram de insumo para a oficina seguinte. Na finalização, convidamos os participantes para a segunda oficina e estabelecemos um calendário para o projeto a pedido deles.

$\mathrm{Na}$ Oficina 2, iniciamos identificando e preenchendo o Diagrama de Partes Interessadas (DPI). O DPI é um artefato usado no processo de design semioparticipativo para apoiar a análise do nível informal de uma organização, ajudando na identificação de qualquer perfil que possa influenciar ou ser influenciado pelo sistema interativo em construção [Baranauskas 2013]. O artefato tem quatro categorias de partes interessadas: contribuição, fonte, mercado e comunidade. Cada categoria representa um tipo de influência, mais ou menos direta, entre uma parte interessada e um sistema interativo. A descrição completa de cada categoria pode ser encontrada em [Baranauskas 2013, p. 53]. O método foi apresentado aos participantes e eles discutiram sobre as partes interessadas ( Ver Figura 1 ). Foram identificadas 18 partes interessadas, como por exemplo: professores, profissionais da saúde, família, acadêmicos e outras instituições.

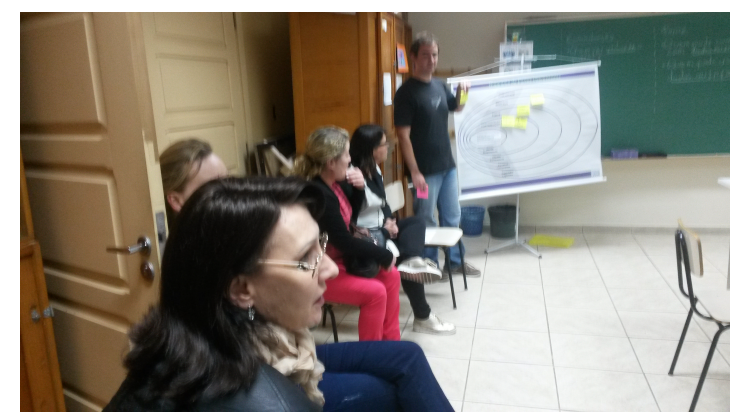

Figura 1. Participantes discutindo as partes interessadas do sistema.

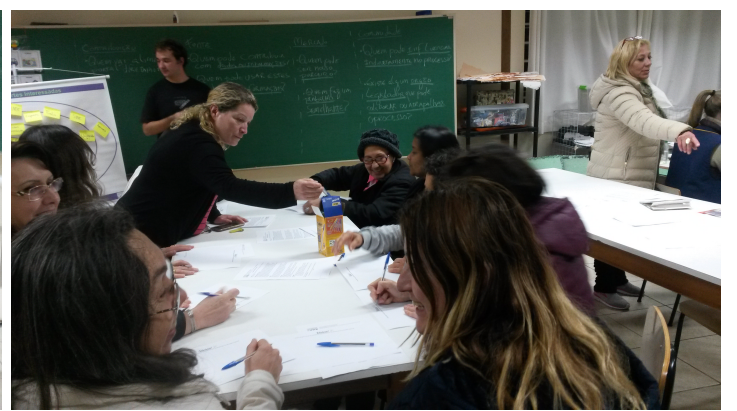

Figura 2. Participantes na atividade do Método de Elicitação em Grupo.

A prática seguinte foi a condução do método de elicitação em grupo (Prática 11.10.27) [Muller et al. 1997]. No primeiro passo, cada participante escreveu todas as suas ideias em um papel. Depois, os participantes passaram a folha para o lado até que todos os outros participantes tivessem visto todas as ideias de seus colegas. Por último, cada grupo escreveu em uma cartolina as dez ideias que consideravam mais importantes para o portal.

Nas Oficinas 3 e 4, decidimos com profissionais da escola que as 20 ideias levantadas na oficina anterior deveriam ser mais detalhadas e debatidas. Isto ocorreu nas duas oficinas seguintes. Em cada oficina, tivemos 6 participantes, que se organizaram em grupos com 3 pessoas. As participantes decidiram detalhar as ideias por prioridade ( Ver Figura 3 ). 
VII Congresso Brasileiro de Informática na Educação (CBIE 2018)

Anais dos Workshops do VII Congresso Brasileiro de Informática na Educação (WCBIE 2018)

Cada ideia foi impressa em uma folha de papel A3 que continha quatro regiões: (1) Uma região para descrever a ideia detalhadamente; (2) Uma região para descrever as vantagens da implementação da ideia; (3) Uma região para identificar quatro partes interessadas mais afetadas pela implementação da ideia; (4) Uma região para observações adicionais.
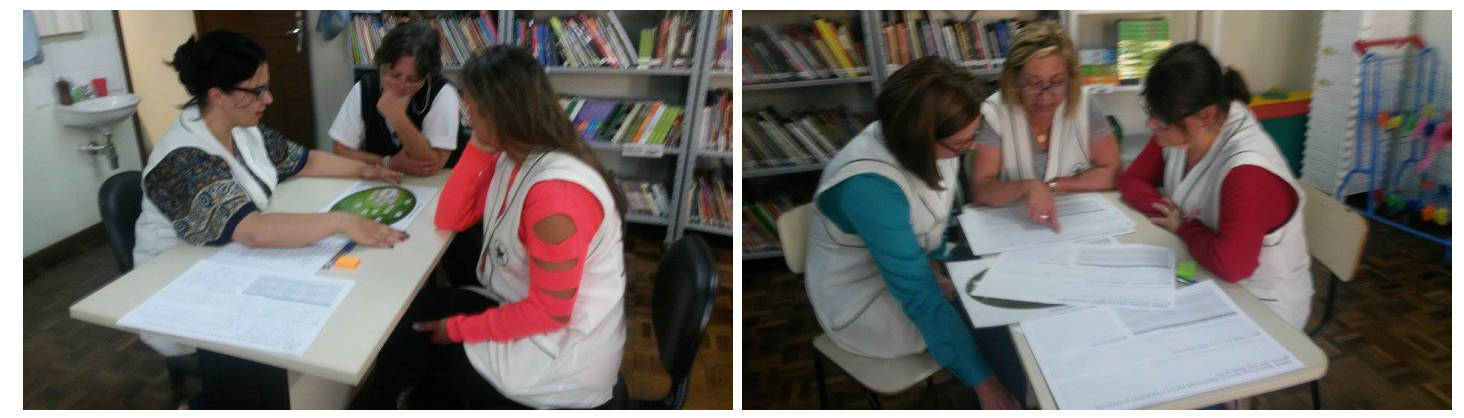

Figura 3. Participantes discutindo e aprofundando ideias geradas na primeira oficina.

As duas primeiras regiões são baseadas na etapa de redução de ideias tipicamente utilizada nos workshops de Engenharia de Requisitos tradicionais. A região 3 tem como objetivo ajudar os participantes a identificar como as partes interessadas podem ser afetadas pela implementação da ideia. Na região 4, os participantes podem escrever qualquer observação que julguem necessária.

As participantes só tiveram tempo para trabalhar em 7 ideias (Tabela 2). Essas ideias foram cuidadosamente debatidas pelas participantes. Ao final da oficina 3, as participantes relataram que os debates foram importantes para elas, uma vez que puderam discutir aspectos sobre suas práticas profissionais.

\begin{tabular}{|c|c|}
\hline 1 & Assessoria pedagógica, atividades pedagógicas, troca de experiências \\
\hline 2 & Dicas para os profissionais da Educação Especial se manterem saudáveis \\
\hline 3 & Videos curtos de práticas pedagógicas \\
\hline 4 & Acesso atualizado ao CID-10 e DSM4 \\
\hline 5 & Chat \\
\hline 6 & Sugestão e acesso a jogos digitais \\
\hline 7 & Ofertas de serviços relacionados à Educação Especial \\
\hline
\end{tabular}

Tabela 2. Ideias que as participantes decidiram detalhar.

$\mathrm{Na}$ reunião periódica seguinte, propusemos mais duas oficinas para completar a discussão das ideias até então não detalhadas. As participantes concordaram em que isto era necessário. Ao mesmo tempo, elas demonstraram preocupação com o fato de que não havíamos apresentado resultados concretos neste encontro - um simples desenho, por exemplo. Apesar do pouco tempo de trabalho dentro das oficinas, cerca de 5 meses já haviam se passado desde a primeira conversa. As participantes demonstraram estar pouco confiantes em relação ao futuro do processo. Por conta disso, abandonamos o plano que havíamos traçado e decidimos com os profissionais da escola apresentar um protótipo funcional na reunião seguinte. 
VII Congresso Brasileiro de Informática na Educação (CBIE 2018)

Anais dos Workshops do VII Congresso Brasileiro de Informática na Educação (WCBIE 2018)

Design do protótipo. Sob a desconfiança de nossos parceiros a respeito do futuro do processo, precisávamos apresentar resultados. Tivemos então de analisar os documentos levantados até o momento e tomar nossas próprias decisões na construção do protótipo. Tomamos duas decisões principais:

- O ambiente será um site de rede social, pois apresentará os elementos descritos na definição de [Ellison et al. 2007]: criação de um perfil público ou semi-público, lista de usuários que partilham uma mesma conexão e acesso à lista de conexões de outros perfis.

- Devido ao pouco tempo que tínhamos para a codificação e apresentação do protótipo, optamos por implementar duas funcionalidades completas baseadas em três ideias detalhadas nas oficinas e duas funcionalidades associadas à estrutura da rede social.

Quatro funcionalidades foram implementados no protótipo: (1) Perfil público, com foto, tags de interesse, nome e descrição. (2) Timeline. (3) Partilha de experiências, caracterizadas por quatro campos: objetivos, materiais, descrição e resultados. Estes campos foram extraídos da análise de 10 documentos (artigos, relatórios e apresentações) sugeridos pelas pesquisadoras da AHIMSA. (4) Sugestão de livros, filmes, notícias e vídeos do Youtube.

Para a Oficina 5, uma avaliação formativa de usabilidade foi realizada. O principal objetivo da oficina era apresentar o resultado concreto as participantes. Além disso, identificar problemas de usabilidade, resgatar questões não implementadas e levantar novas necessidades para redesign na sequência.

Vinte e três professoras compareceram ao grupo de estudo no laboratório da escola. O laboratório tinha apenas sete computadores, e levamos mais dois laptops. Três pesquisadores em Interação Humano-Computador de nosso grupo de pesquisa acompanharam o processo, fazendo anotações. Eles serão chamados de facilitadores.

Para a avaliação, adaptamos aspectos do teste de usabilidade em grupo e juntamos com o método de interação construtiva para suprir as peculiaridades do contexto. No primeiro método, um grupo de usuários trabalha individualmente em uma estação de trabalho, porém sincronizadamente [Downey 2007]. Depois de finalizar a avaliação individual, os avaliadores discutem em grupo o que acabaram de avaliar. O segundo método consiste de uma versão do Thinking Aloud [Kahler et al. 2000] na qual a interação com o sistema é feita em pares.

As participantes se dividiram em grupos de 2-4 pessoas e cada grupo trabalhou em uma estação de trabalho. Cada facilitador ficou responsável por um conjunto de grupos. Os grupos receberam formulários onde puderam anotar problemas e questões durante o processo de execução das tarefas. Foi pedido que as participantes realizassem as mesmas tarefas na mesma sequência para obter resultados mais confiáveis.

As participantes completaram três tarefas: (1) realizar o cadastro no portal, (2) compartilhar uma dica, e (3) socializar uma experiência. Enquanto as participantes executavam as tarefas, os facilitadores faziam as anotações e apoiavam as participantes em caso de dúvidas.

Poucas participantes utilizaram o formulário. Preferiram comunicar as questões e problemas diretamente aos facilitadores. Os facilitadores fizeram cinquenta e oito 
VII Congresso Brasileiro de Informática na Educação (CBIE 2018)

Anais dos Workshops do VII Congresso Brasileiro de Informática na Educação (WCBIE 2018)

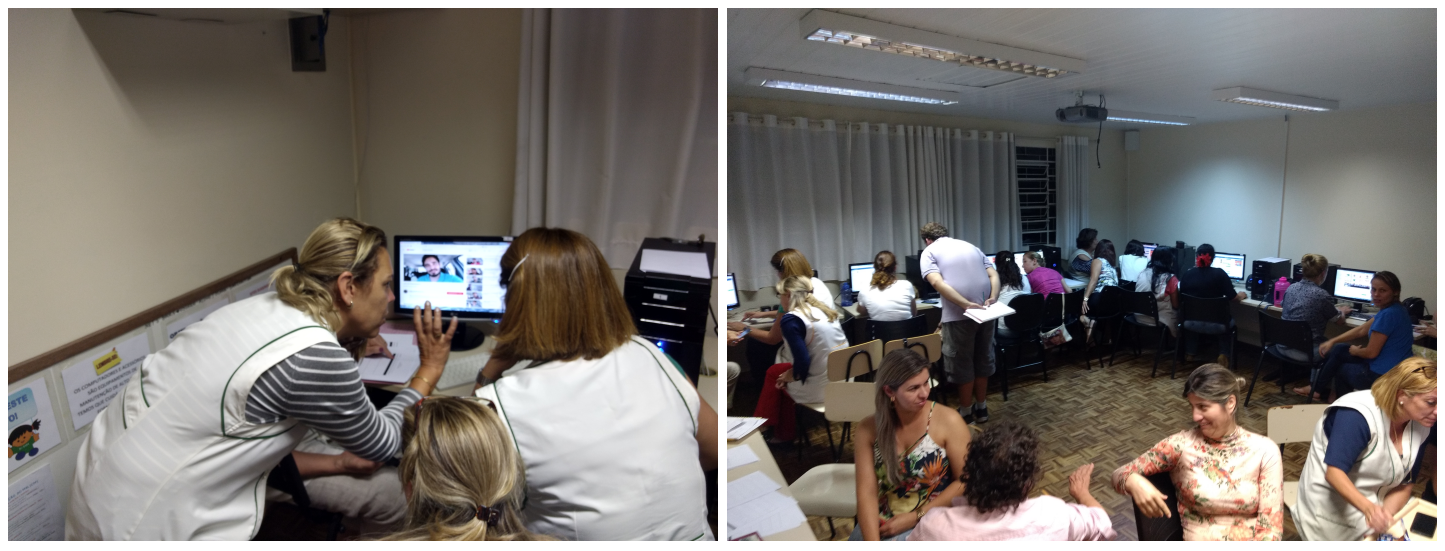

Figura 4. Participantes avaliando o protótipo no laboratório da escola.

anotações no total, que foram agrupadas - removidas as repetições - e classificadas em cinco categorias: inconsistências básicas (16), dificuldade de compreensão (14), sugestões de melhorias no sistema (6), comentários dos facilitadores quanto o comportamento dos participantes (10) e preocupações ou dificuldades com o uso de tecnologia pelos participantes (5).

Foram encontradas muitas inconsistências básicas, que representavam problemas de usabilidade e programação identificáveis sem a necessidade da interação dos participantes com o sistema. A segunda categoria com mais comentários dos facilitadores foi a dificuldade de compreensão. Isto se deu por problemas de comunicabilidade do sistema de determinados aspectos de domínio computacional. Por exemplo, grande parte das participantes não sabia o significado do campo "Tag" ou para que servia o campo "Interesses". O sistema falhou ao comunicar a tarefa 2: grande parte dos participantes utilizou o recurso de partilha de experiência, enquanto era esperado que utilizassem o recurso de sugestão.

Os facilitadores captaram muitas reações positivas das participantes durante a avaliação. Elas estavam engajados na tarefa de compartilhar, buscando informações em outras fontes fora do sistema que estavam explorando e discutindo com as colegas as potencialidades e problemas do sistema. Durante a atividade, foram realizadas trinta e uma publicações, sendo: comentário (12), partilhar experiência (10), sugestão de livro (5), sugestão de filme (3) e sugestão de vídeo (1). O recurso de sugestão de notícia não foi utilizado.

Apenas quatro das dez partilhas de experiência utilizaram o campo de Tags para comunicar algo a respeito do conteúdo. Muitas publicações continham links para sites externos nas tags. Apenas duas publicações não estavam diretamente relacionadas à Educação Especial. Porém, estas duas estavam relacionadas à Educação e ao bem-estar das profissionais. No final da atividade, muitas participantes perguntaram se o sistema estaria acessível em outros dias e uma reunião foi marcada para darmos continuidade do projeto.

\section{Lições Aprendidas}

Desde o princípio do projeto nossa preocupação central foi endereçar as reais necessidades dos profissionais da educação especial, na perspectiva de semear a continuidade 
do que fosse ser construído. A concepção do projeto partiu das angústias e necessidades trazidas por profissionais da área e do estudo dos fatores envolvendo o APC que nos reafirmou ser necessário o envolvimento dos atores da educação nas tomadas de decisão sobre tecnologias educacionais que afetarão suas vidas.

As ideias trazidas pelos profissionais da escola parceira mostram que eles querem, também, um espaço para cuidar de sua saúde. Nossas concepções iniciais enxergavam apenas a formação continuada, como o APC considerava. Para além destas concepções, percebemos que devemos buscar construir com eles espaços adicionais para incluir a promoção de seu bem estar e do desenvolvimento pessoal.

As oficinas ocorreram em diversos espaços na escola e foram momentos de discussões e aprendizado. Por exemplo, na oficina 3, um grupo de professoras fez uma discussão sobre os códigos CID-10 e DSM4 para além do seus possíveis papéis no sistema. A disponibilização dos horários dos grupos de estudo na escola para a realização das oficinas e o bom número de professores participantes nelas demonstraram uma predisposição da escola e sua equipe em receber projetos de parceria para a criação de tecnologias educacionais.

Um momento crítico desta primeira etapa ocorreu quando os professores manifestaram sua desconfiança em relação ao o projeto pela falta de um resultado concreto. Apesar da preocupação desde o começo com o envolvimento dos profissionais nas decisões sobre o sistema em desenvolvimento, éramos nós que tomávamos todas as decisões do processo de design. Este retorno nos ensinou que é preciso dialogar com os profissionais sobre como o processo deve se situar dentro da realidade deles e sobre quais as suas expectativas no decorrer do processo. Isto determinou uma outra postura: ao mesmo tempo que buscamos mais diálogo com os profissionais nas tomadas de decisão sobre os passos seguintes do projeto, buscamos também realizar práticas que direcionassem para ações concretas no sistema.

\section{Conclusão}

Neste trabalho, apresentamos o processo de construção de um protótipo de uma rede social no qual profissionais da Educação Especial poderão partilhar questões de seu interesse. Com esse intuito, buscamos envolver atores educacionais que tipicamente são excluídos dos processos de construção de tecnologias educacionais.

Mostramos que, ao considerar as necessidades dos profissionais da Educação Especial desde a concepção de uma tecnologia, é possível endereçar questões que realmente importam para eles. Além disso, nosso aprendizado mostra que é preciso dialogar com os profissionais e com a escola nas tomadas de decisão do processo de design. Abandonamos concepções iniciais sobre o ambiente, que passaram de focar um ambiente de formação continuada dos profissionais para um espaço próprio para eles, com recursos que eles acham prioritários na sua realidade social.

Mostramos, também, que é possível se situar, enquanto designers e desenvolvedores, dentro da escola, adaptando-se às suas peculiaridades e seus espaços físicos, para construir não somente a tecnologia em si, mas, principalmente, experiências democráticas com ela.

Como desafios, temos a construção conjunta de uma versão mais completa do 
VII Congresso Brasileiro de Informática na Educação (CBIE 2018)

Anais dos Workshops do VII Congresso Brasileiro de Informática na Educação (WCBIE 2018)

protótipo, da apropriação e uso deste pelos profissionais das escolas envolvidas, da extensão para uma comunidade mais ampla e, mais importante ainda, da construção conjunta do processo continuado de DP.

\section{Referências}

Baranauskas, M.C.C.; Mantoan, M. (2014). Todos nós em rede: Relatório final de cumprimento do objeto. Relatório técnico.

Baranauskas, M. C. C. (2013). O modelo semioparticipativo de design. Codesign De Redes Digitais-Tecnologia e Educação à Serviço da Inclusão, Penso, 1:38-66.

Barcelos, G. T., Passerino, L. M., and Behar, P. A. (2013). Formação continuada com apoio de uma rede social na internet: Tecnologias na prática docente de professores de matemática. Revista Brasileira de Informática na Educação, 21(2).

Basniak, M. I. (2016). Políticas de tecnologias na educação: o Programa Paraná Digital. Educar em Revista, pages 305 - 319.

Borges, K. S., Nichele, A. G., and de Menezes, C. S. (2016). Formação continuada de professores através de comunidades de prática: um estudo de caso. Revista Brasileira de Informática na Educação, 24(2).

Castilho, M., Sunyé, M., Weingaertner, D., de Bona, L., Silva, F., Carvalho, C., García, L., Guedes, A., and Direne, A. (2007). Laboratórios de informática com software livre para atender políticas estaduais do ensino escolar. In Anais do Workshop de Informática na Escola, volume 1.

da Silva, W. R. and Prietch, S. S. (2016). Wikitas: Online collaboration concerning with assistive technologies for teachers of students who are deaf. In Proceedings of the 15th Brazilian Symposium on Human Factors in Computer Systems, page 41. ACM.

Downey, L. L. (2007). Group usability testing: Evolution in usability techniques. Journal of Usability Studies, 2(3):133-144.

Ehn, P. (2017). Learning in participatory design as i found it (1970-2015). In Participatory Design for Learning. Routledge.

Ellison, N. B. et al. (2007). Social network sites: Definition, history, and scholarship. Journal of computer-mediated Communication, 13(1):210-230.

Kahler, H., Kensing, F., and Muller, M. (2000). Methods \& tools: constructive interaction and collaborative work: introducing a method for testing collaborative systems. interactions, 7(3):27-34.

Kensing, F. and Greenbaum, J. (2013). Heritage: having a say. In Routledge international handbook of participatory design, pages 21-36. Routledge.

Menezes, G. G. d. (2008). Ambiente pedagógico colaborativo do Portal Dia-a-Dia Educaçăo: análise do modelo didático-tecnológico. $\mathrm{PhD}$ thesis, Universidade Federal do Paraná.

Muller, M. J., Haslwanter, J. H., and Dayton, T. (1997). Participatory practices in the software lifecycle. Handbook of human-computer interaction, 2:255-297. 